\title{
Study of the Prevalence and Pattern of Anaemia in Unmarried Anaemic Females Aged (15-30 Years)
}

\author{
Rahul Dudwe ${ }^{1}$, Neelima Singh ${ }^{2 *}$ \\ ${ }^{1}$ Junior Resident III, Department of Medicine, G. R. Medical College, Gwalior, India \\ ${ }^{2}$ Associate Professor, Department of Medicine, G. R. Medical College, Gwalior, India
}

*Address for Correspondence: Dr. Neelima Singh, Associate Professor, Department of Medicine, G. R. Medical College, Gwalior, Madhya Pradesh-474002, India

E-mail: neelimajadon@yahoo.com

Received: 05 Oct 2019/ Revised: 29 Nov 2019/ Accepted: 02 Jan 2020

\begin{abstract}
Background: Anemia is one of the most usual causes of malnutrition and around $30 \%$ of the world populations are suffering from Anemia. Infants, pre-school children, adolescents, and particularly women are at greatest risk of developing anemia. About $56 \%$ of pregnant women in developing countries and $18 \%$ in the developed countries are anemic. The estimated prevalence of anemia in non-pregnant women is $43 \%$ in developing country and $12 \%$ in developed countries.

Methods: A Prospective cross sectional observational study consisting of total 100 cases of anaemia was underlined to study the prevalence and pattern of anaemia in unmarried females age group between 15-30 years. A pre-tested and pre-designed performa was used to collect the information on socio-demographic characteristics like age, family size, family type, educational status, parental educational status, monthly family income, history of worm infestation, history of intake of iron supplements and dietary history, and body mass index (BMI). The systematic examination included cardiovascular system (CVS), respiratory system (RS), per abdomen (PA) and central nervous system (CNS).

Results: The prevalence of anemia was slightly higher in unmarried women of age 21 years and $82 \%$ were vegetarians and $18 \%$ among non-vegetarians. Total 43 women had a BMI of 18.5-24.9 or above. Anemia was high in lower class family, nearly half, 52 women belong to the family had monthly income of less than 10 thousand. Maximum cases of anemia had $\mathrm{Hb} \%$ levels in the range of 10.1-11.0 g\%. Out of 100 cases, 19 were of normocytic normochromic type; 67 were of microctic hypochromic type and 14 were of macrocytic type.

Conclusion: Anemia is, thus impediment to individual and National development. With the focus on the health of women in general and the adolescent girl in particular, the picture of anemia seen is alarming. The study results indicated that the anemia prevalence rate was specifically higher in unmarried female's age group between 15 to 30 years. With the fluency of study in terms of peripheral blood smear, $19 \%$ cases of normocytic normochromic anemia, $14 \%$ cases of macrocytic anemia and $67 \%$ of cases of microcytic anemia (most of them iron deficiency anemia) was observed.
\end{abstract}

Key-words: Adolescence, Anaemia, CKD, Hemoglobin concentration, Prevalence

\section{INTRODUCTION}

Anaemia is one among the foremost common causes of malnutrition and around $30 \%$ of the world populations are suffering from Anemia. Approximately 56\% of pregnant women in developing countries and $18 \%$ in the developed countries are anaemic ${ }^{[1]}$.

\section{How to cite this article}

Dudwe R, Singh N. Study of the Prevalence and Pattern of Anaemia in Unmarried Anaemic Females Aged (15-30 Years). SSR Inst. Int. J. Life Sci., 2020; 6(1): 2469-2479.

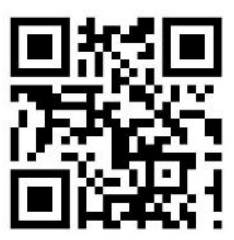

The estimated prevalence of anaemia in non-pregnant women is $43 \%$ in developing country and $12 \%$ in developed countries, respectively ${ }^{[1]}$.

Numerous factors, like sex, age, residential altitude, smoking behaviour, pregnancy status influence, and hemoglobin concentration ${ }^{[2]}$. Additionally to being a medical condition, anemia is an important socioeconomic issue given its association with diminished physical and cognitive productivity [3]. A complex interplay of political, ecological, social, and biological factors determines the prevalence and distribution of anemia in a population ${ }^{[4]}$. Previous surveys have documented several potential causes of 
anaemia among women including rural residency [4], younger age ${ }^{[5]}$, pregnancy status ${ }^{[6,7]}$, lower nutritional status ${ }^{[5]}$, repeated childbearing ${ }^{[8]}$, lactation/ breast feeding ${ }^{[5,6]}$, poor access to nutritional supplements during pregnancy ${ }^{[5]}$, and exposure to household violence ${ }^{[9]}$. Additionally, helminth infection ${ }^{[10]}$ and malaria [11] found to be important causes of anemia. Furthermore, anaemia was found to be associated with immunologic disease progression and increased risk of AIDS-related death ${ }^{[12]}$. On the contrary, the use of hormonal contraceptives was shown to cause a potential protective effect against anaemia ${ }^{[13]}$.

Women have extra requirements of iron supplements upon puberty to menopause due to physiological requirements, including menstruation, pregnancy and lactation (to some extent). For this extend, women of reproductive age get to suffer from iron deficiency even in developed countries throughout their reproductive years ${ }^{[14,15]}$. During adolescence, the spurt growth required additional amount of iron, and for the girl, there's furthermore requirement of iron due to regular menstrual loss.

The prevalence of anaemia increases during growth and development when there is an increased need for an iron-rich diet ${ }^{[16,17]}$. More than $30 \%$ of patients admitted to hospitals in developed nations are reported to be anemic, and this rate was known to be higher in developing countries and among women ${ }^{[17]}$.

The factors responsible for the high prevalence of anaemia are varying consistent with geographical location. Iron deficiency is by far the one of the important causes of nutritional anaemia in public health terms. The prevalence of anaemia is alarmingly high in India due to (I) low dietary intake of iron ( $<20 \mathrm{mg} /$ day) and folic acid intake $(<70 \mathrm{mg} /$ day); (II) poor bioavailability of iron ( $3-4 \%$ only) in phytate and fiberrich Indian diet; and (III) chronic blood loss due to infection such as malaria and hookworm infestations, (IV), when bodily requirements of iron increase, or in cases of excessive blood loss ${ }^{[18,19]}$.

The poor intake of folate during haemolysis associated with malaria can exacerbate the anaemic state. Plasmodium falciparum malaria is a major contributing factor to severe anaemia in the primigravida [20]. Anaemia also caused due to deficiency of vitamin B12, vitamin $A$, as well as zinc however the amount of these deficiencies in the region has not been determined.
HIV/AIDS is ranked high as determinant of anaemia in women and its prevalence is increasing in women of reproductive age ${ }^{[21,22]}$. Opportunistic infections and dietary deficiencies in AIDS patients are associated with anaemia. Also, an independent effect of HIV infection on haemoglobin concentration that is not associated with concurrent infection or dietary deficiency has been demonstrated ${ }^{[23]}$.

\section{MATERIALS AND METHODS}

Study design- The study was scheduled to be completed in the time duration from Jan 2018 to Jun 2019. Data for this study was obtained from indoor wards and outdoor wards of Department of Medicine, G. R. Medical College, Gwalior, Madhya Pradesh, India. A prospective cross sectional observational study consisting of total 100 cases of anaemia with abdominal pain underlined to study was to examine the study of the prevalence and pattern of anaemia in unmarried females aged (15-30 years).

Inclusion Criteria- Young, unmarried anaemic females in age group range of $15-30$ years.

Exclusion Criteria- Critically ill patients.

Data collection technique and Tools- A pre-tested and pre-designed performa was used to collect the knowledge on socio-demographic characteristics like age, educational status, family size, family type, monthly family income, parental educational status, history of worm infestation, history of intake of iron supplements and dietary history, BMI. The systematic examination included CVS, RS, PA and CNS. The lab investigation included Complete Blood Count (CBC) with Peripheral Smear, Hematological Indices [Mean Corpuscular Volume (MCV), Mean Corpuscular $\mathrm{Hb}(\mathrm{MCH})$, and Mean Cell Hemoglobin Concentration (MCHC)], Reticulocyte Count, and Stool for occult blood and RFT, 24 hour Urine for Protein, Urine R/M and Ultrasonography Abdomen. For interpretation of anaemia, the cut-off point for hemoglobin level taken as $12 \mathrm{~g} / \mathrm{dl}$. The severity of anaemia was graded as mild (10-11.9 gm/ dl), moderate (7-7.9 gm/dl) and severe (<7.0 gm/dl). In our study, we were supplement hematinics to correct anaemia and treat other causes of anaemia. 
Statistical Analysis- The data collected was transferred to a pre-designed classified table, which was according to our study. The data analysis was done to draw the valid references. Statistical analysis of data collected will be done by finding mean values, standard deviation, frequency and Chi square test using SPSS version 25.0 software.

\section{RESULTS}

The data for this study was collected from 100 unmarried females, who were anemic. It was organized as follows; descriptive information of the study variables, analysis of factors associated with anaemia and final multivariate analysis summarizing the prevalence and pattern of anaemia among unmarried women aged between 15 years to 30 years women. The results were presented in tables and graph forms.

Prevalence of anaemia by age- The prevalence of anaemia was slightly higher in unmarried women of age 21 years. The mean age was 22.74 years (Table 1 and Fig. $1)$.

Table 1: Parent's age distribution, frequency and mean value

\begin{tabular}{|c|c|c|c|}
\hline S. No. & Age & No. of Cases & Mean age $\pm S D$ \\
\hline 1. & 15 years & 5 & \multirow{16}{*}{$22.74 \pm 4.46$} \\
\hline 2. & 16 years & 7 & \\
\hline 3. & 17 years & 7 & \\
\hline 4. & 18 years & 4 & \\
\hline 5. & 19 years & 2 & \\
\hline 6. & 20 years & 4 & \\
\hline 7. & 21 years & 11 & \\
\hline 8. & 22 years & 8 & \\
\hline 9. & 23 years & 7 & \\
\hline 10. & 24 years & 6 & \\
\hline 11. & 25 years & 8 & \\
\hline 12. & 26 years & 6 & \\
\hline 13. & 27 years & 6 & \\
\hline 14. & 28 years & 7 & \\
\hline 15. & 29 years & 8 & \\
\hline 16. & 30 years & 4 & \\
\hline
\end{tabular}




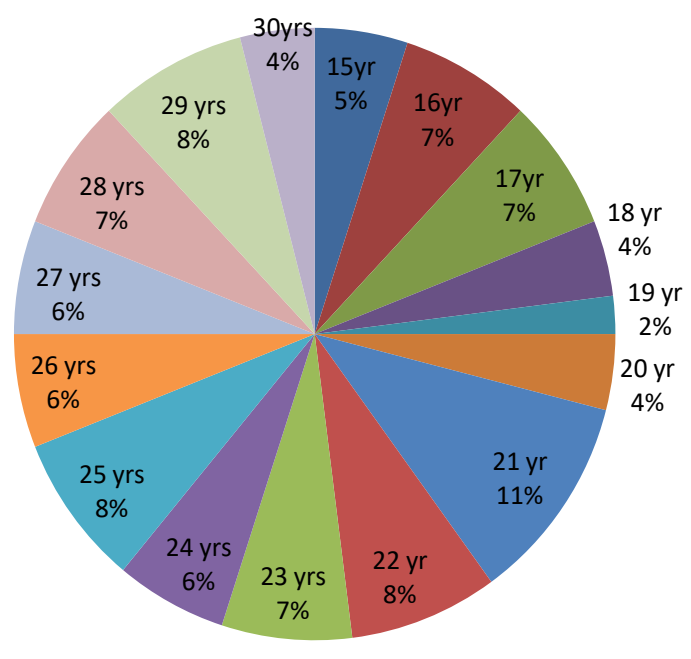

Frequency of Cases

Fig. 1: Age distribution and frequency of unmarried anaemic women aged between 15 to 30 years

Prevalence of anaemia by diet- In general, the prevalence of anaemia was found lower in those, who had taken non-vegetarian diet. The prevalence of anaemia among vegetarians was 4.5 times higher as compared to non-vegetarians. In studied cases, the prevalence was $82 \%$ among vegetarians and $18 \%$ among non-vegetarians (Table 2 and Fig. 2).

Table 2: Prevalence of anaemia by type of diet in unmarried women aged between $15-30$ years

\begin{tabular}{ccc}
\hline S. No. & Diet type & Patients (\%) \\
\hline 1. & Vegetarian & 82 \\
2. & Non-vegetarian & 18
\end{tabular}

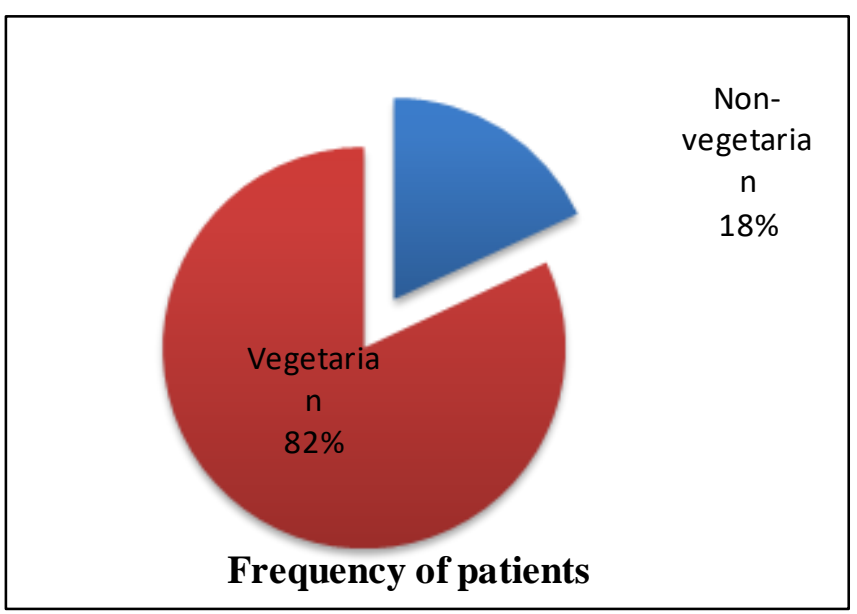

Fig. 2: Frequency of anaemia by type of diet in unmarried women aged between $15-30$ years

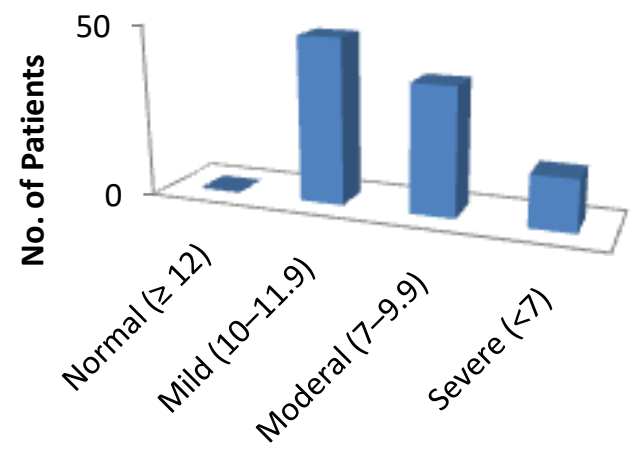

$\mathrm{Hb} \%$

\section{Haemoglobin percentage}

Fig. 3: Severity of anaemia among unmarried anaemic women aged between $15-30$ years

Prevalence of anaemia on the basis of different variables- Forty three women had a BMI of 18.5-24.9 or above. Regarding the educational level of the cases 23 , 49 and 19 attended primary, secondary and tertiary level of education, respectively. Total 13 women belong to the small family (up to 3 members), 62 belong to medium family and 25 women belong to a large family. The prevalence of anaemia was high in lower class family, nearly half, 52 women belong to the family had monthly income of less than 10 thousand. 28 women belong to the family had monthly income between 11 thousand to 30 thousand. Twelve women belong to the family had monthly income between 31 thousand to 50 thousand. Eight women belong to the family had monthly income above 50 thousand. The prevalence of anaemia decreases as the educational status of parents increases in rural area. Worm infection was predicted in 14 cases. The iron supplements were taken only by 29 women. 
Table 3: Prevalence of anaemia in unmarred women's aged between 15 to 30 years on the bases of different variables

\begin{tabular}{|c|c|}
\hline Variables & No. of patients \\
\hline \multicolumn{2}{|l|}{ BMI } \\
\hline$<18.5$ & 39 \\
\hline $18.5-24.9$ & 43 \\
\hline$>24.9$ & 18 \\
\hline \multicolumn{2}{|l|}{ Educational status } \\
\hline None & 9 \\
\hline Primary level & 23 \\
\hline Higher level & 49 \\
\hline Tertiary level & 19 \\
\hline \multicolumn{2}{|l|}{ Family type (Class) } \\
\hline Low & 52 \\
\hline Middle & 39 \\
\hline High & 9 \\
\hline \multicolumn{2}{|l|}{ Family size } \\
\hline \multicolumn{2}{|l|}{ Small Family (Up to 3 Members) } \\
\hline Medium Family (4-6 Members) & 13 \\
\hline Large Family( $\geq 7$ Members) & 62 \\
\hline & 25 \\
\hline \multicolumn{2}{|l|}{ Monthly family income } \\
\hline$<10$ thousand & 52 \\
\hline 11 thousand to 30 thousand & 28 \\
\hline 31 thousand to 50 thousand & 12 \\
\hline$>50$ thousand & 8 \\
\hline \multicolumn{2}{|l|}{ Parents educational status } \\
\hline \multicolumn{2}{|l|}{ FATHER } \\
\hline Primary & 77 \\
\hline Middle & 32 \\
\hline High School & 9 \\
\hline \multicolumn{2}{|l|}{ MOTHER } \\
\hline Primary & 59 \\
\hline Middle & 20 \\
\hline High School & 3 \\
\hline \multicolumn{2}{|l|}{ History of worm infection } \\
\hline Present & 21 \\
\hline Absent & 79 \\
\hline \multicolumn{2}{|l|}{ History of iron supplements taken } \\
\hline Yes & 14 \\
\hline No & 71 \\
\hline
\end{tabular}

Prevalence of anaemia among patients at various ranges of hemoglobin percentage- Maximum cases of anemia had $\mathrm{Hb} \%$ levels in the range of $10.1-11.0 \mathrm{~g} \%$ and 7.1-8.0\%; followed by 8.1-9.0 g\%, 6.1-7.0 g\%, 11.1-12.0 g\%, 5.1-6.0 g\% and 4.1-5.0 g\%, 9.1-10.0 g\% respectively, whereas minimum cases of anemia had $\mathrm{Hb} \%$ levels in the range of $2.1-3.0 \mathrm{~g} \%$. The mean value for $\mathrm{Hb} \%$ was $8.90 \pm 1.68$.

Table 4: Frequency of anaemic patients at various ranges of hemoglobin percentage

\begin{tabular}{cccc}
\hline S. No. & $\mathbf{H b}(\%)$ & No. of cases & Mean \pm SD \\
\hline 1. & $2.1-3.0$ & 2 & \\
2. & $3.1-4.0$ & 5 & \\
3. & $4.1-5.0$ & 7 & \\
4. & $5.1-6.0$ & 9 & $100 \pm 5.05$ \\
5. & $6.1-7.0$ & 12 & \\
6. & $7.1-8.0$ & 16 & \\
7. & $8.1-9.0$ & 14 & \\
8. & $9.1-10.0$ & 7 & \\
9. & $10.1-11.0$ & 18 & \\
10. & $11.1-12.0$ & 10 & \\
\hline
\end{tabular}

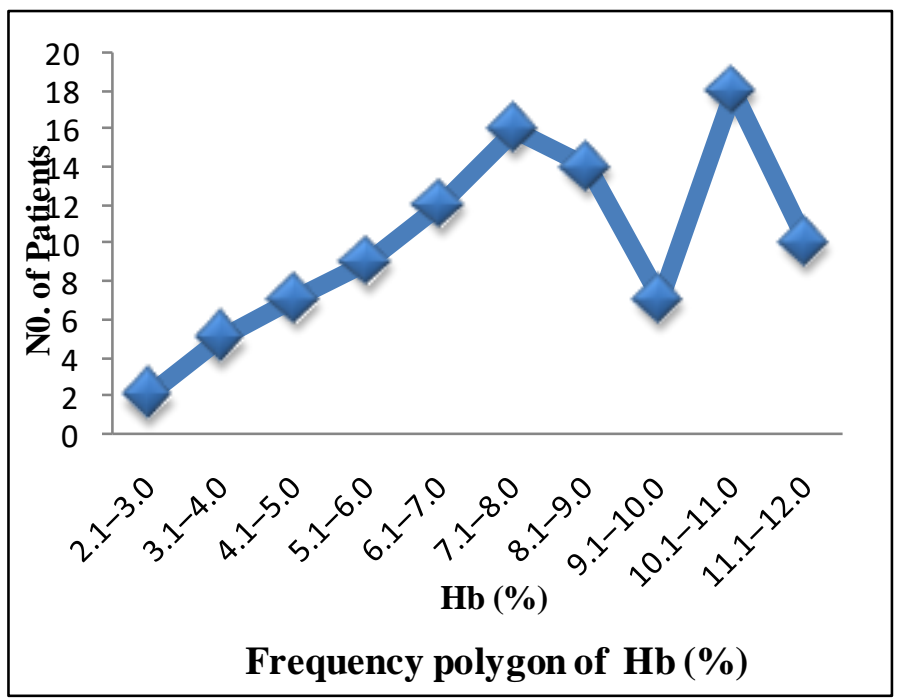

Fig. 4: Frequency polygon of hemoglobin percentage in unmarried anaemic women aged between 15 years to 30 years

Prevalence of co-morbid illness- Diabetes Mellitus (DM) was present in $6 \%$ cases, where as HTN was present only in $4 \%$ of cases. Hypothyroidism was present in $8 \%$ of cases and only $2 \%$ cases were suffering from SLE. RA was present only in one case, malaria infection was present in $3 \%$ cases, $2 \%$ cases were identified with HIV infection whereas PTB was present in $10 \%$ cases. CKD was identified only in $3 \%$ cases. 
Table 5: Prevalence of co-morbid illness in anaemic unmarried women aged between 15 to 30 years

\begin{tabular}{|c|c|c|c|}
\hline S. No. & Co-morbid illness & Patients & Patients (\%) \\
\hline \multirow[t]{2}{*}{1.} & \multirow{2}{*}{ DM } & Present & 6 \\
\hline & & Absent & 94 \\
\hline \multirow[t]{2}{*}{2.} & & Present & 4 \\
\hline & HTN & Absent & 96 \\
\hline \multirow[t]{2}{*}{3.} & Hupothurgidicm & Present & 8 \\
\hline & Hypotnyroialsm & Absent & 92 \\
\hline \multirow[t]{2}{*}{4.} & & Present & 2 \\
\hline & SLE & Absent & 98 \\
\hline \multirow[t]{2}{*}{5} & BA & Present & 3 \\
\hline & & Absent & 97 \\
\hline \multirow[t]{2}{*}{6.} & Malaria Infection & Present & 5 \\
\hline & & Absent & 95 \\
\hline \multirow[t]{2}{*}{7.} & & Present & 2 \\
\hline & HIV Intection & Absent & 98 \\
\hline \multirow[t]{2}{*}{8.} & & Present & 10 \\
\hline & PIB Intection & Absent & 90 \\
\hline \multirow[t]{2}{*}{6.} & CKD & Present & 3 \\
\hline & & Absent & 97 \\
\hline
\end{tabular}

DM= Diabetes Mellitus, HTN= Hypertension, SLE= Systemic lupus erythematosus, RA= Rheumatoid Arthritis, PTB= Pulmonary tuberculosis, CKD= Chronic kidney disease

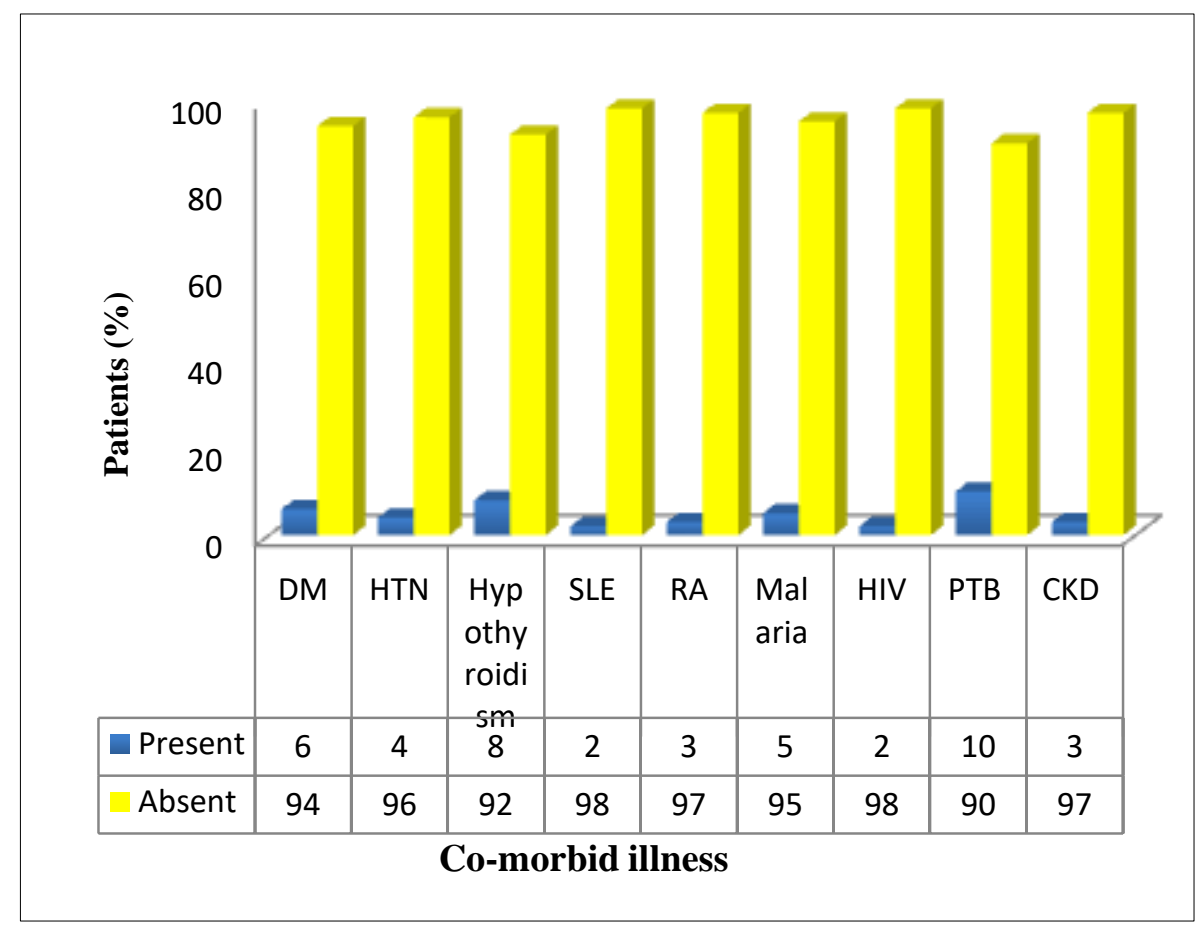

Fig. 5: Frequency of co-morbid illness among cases 
Peripheral smear- Out of 100 cases, 19 were of Normocytic normochromic type (NCNC) type; 67 were of Microctic hypochromic (MCHC) type and 14 were of Macrocytic type (MA) type.

Table 6: Morphological classification of anemia of unmarried anemic female patients based on peripheral blood smear

\begin{tabular}{ccc}
\hline S. No. & $\begin{array}{c}\text { Peripheral Blood } \\
\text { Smear }\end{array}$ & $\begin{array}{c}\text { Total No. of } \\
\text { Cases }\end{array}$ \\
\hline 1. & NCNC & 19 \\
2. & MCHC & 67 \\
3. & MA & 14 \\
\hline
\end{tabular}

NCNC- Normocytic normochromic type, MCHC- Microctic hypochromic, MA- Macrocytic type

\section{DISCUSSION}

The present study, included 100 unmarried anaemic women cases between 15 years to 30 years, attending Department of Medicine, G. R. Medical College \& J.A. Group of hospitals Gwalior, Madhya Pradesh, India. This discussion, analysis data obtained from the study and compared it to obtained previous studies done with similar objectives in mind.

Overall, anaemia prevalence was found more in $21 \mathrm{yr}$ old age of adolescent. Anaemia prevalence of more than $40 \%$ has been defined as a problem of severe public health significance by WHO ${ }^{[1]}$ for epidemiological mapping. There were two peaks in iron deficiency anaemia i.e. 21-22 yrs and 29-30 yrs, suggesting the majority of patients with iron deficiency anaemia. As per WHO classification, the majority of the subjects suffered from mild anaemia (48\%). While $37 \%$ and $15 \%$ suffered from moderate and severe anaemia, respectively. Similar results were reported by CMS Rawat et al. ${ }^{[24]}$ as well as Varma et al. ${ }^{[25]}$, where they noted high incidence of mild to moderate anaemia. In this study, $37 \%$ of anaemic subjects had low MCV with high RDW, suggestive of probably iron deficiency.

Prevalence of anaemia when analyzed by socioeconomic factors showed that education of parents, family type, supplements of iron and socio-economic status was associated significantly with anaemia. The similar studies were done by Rawat ${ }^{[24]}$ and Verma et al. ${ }^{[25]}$ supported our findings. This may be because of better availability of high quality food with better socio economic status and better understanding of the needs of the adolescent girls by the parents. Since majority, $80 \%$ of the participants had monthly income of less than 30 thousand; the high prevalence of anaemia during this study was mostly associated with the low socioeconomic status of the women, which have an impact on their nutritional status and health seeking behavior [26]. Women in low socio-economic classes are likely to be poorly educated and sometimes have financial constraints. These women cannot afford good health services or they could not have access to health services. The result was that they suffered the deleterious effects of poor nutrition, HIV, chronic infections and worm infestations.

The prevalence of anaemia was more in the cases prefer vegetarian food. Bioavailability of iron from cereals and vegetables was low because of the presence of phytates, oxalates and tannins. Although no assessment of dietary intake was made, the diet in the study area was predominantly of cereals and vegetables. This type of diet provides low amounts of bioavailable iron because of the high content of iron absorption inhibitors, such as phytate and polyphenols ${ }^{[1]}$. The typical Indian diet is based on cereals and pulses, which contain more than $40 \%$ of total phosphorus as phytates and vegetables and plant food contain oxalates, which interfere with absorption of food iron inspire of high dietary intake.

$\mathrm{BMI}$ is the most practical and widely used tool to determine an individual's body fat mass. As per WHO BMI charts 2007, the subjects were classified, and it was observed that women falling into the category of $<3^{\text {rd }}$ to $15^{\text {th }}$ percentile had a high prevalence of anaemia. This is inconsistent with the study conducted by Kannani and Poojara ${ }^{[27]}$.

This study revealed that the risk of developing anaemia was significantly more among women who did not take iron and folic acid supplements compared to those who took these supplements. This finding was in line with other previous studies such as Ethiopia (Kefyalew and Abdulahi ${ }^{[28]}$; Abel Gebre and Afework Mulugeta ${ }^{[29]}$ ), Uganda (Sam et al. ${ }^{[30]}$ ), Nigeria (Nwizu et al. ${ }^{[31]}$ ), Vietnam (Fujimori et al. ${ }^{[32]}$ ) and India (Thirukkanesh and Zahara, ${ }^{[33]}$, Khan et al. ${ }^{[34]}$ and Aikawa et al. ${ }^{[35]}$ ), which indicated that lack of iron supplementation among the most significant risk factors for developing countries.

Lower personal income, an incomplete secondary school education, food insecurity and the status of being single were associated with iron deficiency while employed 
women had a better overall iron status than non-working women. Similar results have been reported elsewhere [36]. However, since many of these characteristics may be age related factors, their real influence on iron status must be precisely studied, considering the confounding effect of age.

Successful management of anaemia depends on reliable means for detecting anaemia, assessing its severity and monitoring response to treatment. Screening for anaemia in women is useful for a variety of reasons. It may help to collect baseline data on the prevalence of anaemia and severity in a given population. Recently, the WHO colour scale was validated and found to be useful in tropical field conditions (Van den Broek et al. ${ }^{[37]}$ ), and its advantage over clinical signs confirmed by Ingram and Lewis ${ }^{[38]}$. Provision of these essential facilities motivates women to attend the clinic, and also may improve compliance with treatment. A study by Koblinsky [36], women diagnosed as anaemic found supplementation more acceptable. Testing would promote a better understanding of anaemia by women.

Malaria causes severe anaemia. In this study, we found that the prevalence of anaemia was significantly higher, and the mean haemoglobin significantly lower in women with a positive malaria test. These findings were consistent with other studies given by Brabin and Piper [20]; and Shulman et al. ${ }^{[39]}$. In addition, they were also iron-deficient. However, HIV-positive women have also increased susceptibility to malaria.

The HIV prevalence was smaller among unmarried women. HIV-infected women are at an increased risk of anaemia, and severe anaemia (Antelman et al. ${ }^{\text {[40]; Van }}$ den Broek et al. ${ }^{[23]}$ ). The increased risk of anaemia is thought to be associated with a higher degree of severity of the disease. However, in populations with a high risk of exposure to infectious diseases, particularly malaria, the vicious cycle of infections, impaired immunity and anaemia may result in a stronger association between HIV infection and anaemia already at an earlier stage of the disease. $70 \%$ of people with AIDS are anaemic, and AIDS, TB and related infections are ranked ly as major determinants of anaemia in reproductive age women by UNICEF, ${ }^{[22]}$. A study given by Zucker et al. ${ }^{[41]}$ showed that severely anaemic women of reproductive age were significantly more likely to be HIV-positive.

Infections interfere with iron absorption and uptake in the bone marrow and thus contribute to anaemia. Most likely sites of sub-acute and chronic infections could be in the urinary tract and in the respiratory tract, including TB. Van den Broek and Letsky ${ }^{[42]}$ showed that infections were common among both HIV-positive anaemic and negative anaemic women. Tatala et al. ${ }^{[43]}$ reported in 1998 that Hookworm is prevalent for anaemia and contributes to anaemia in various groups of the population including women and children. In the anaemic women studied, the presence of hookworm was associated with severe anaemia.

The contribution of hookworm to anaemia is dependent on hookworm load. However, in the context of a poor diet and low body iron stores, light to moderate hookworm infection is sufficient to cause anaemia. Stoltzfus et al. ${ }^{[44]}$ concluded that women of reproductive age are susceptible to anaemia because their iron stores are inadequate in hookworm endemic areas. 52\% of cases with moderate to severe anaemia among studies cases women were attributed to hookworm. Hookworm control is therefore an essential component of anaemia control that could be achieved through community education on sanitary practices and also periodic deworming of groups vulnerable for anaemia, especially school girls given be UNICEF ${ }^{[45]}$. De-worming of women has been shown to significantly increase the beneficial effects of iron supplementation on $\mathrm{Hb}$ concentration and iron status by Atukorala et al. ${ }^{[45]}$.

The anaemia of CKD was generally normocytic normochromic. The presence of microcytosis reflects iron deficiency and aluminium excess, whereas macrocytosis reflects vitamin $B_{12}$ or folate deficiency and/or erythropoietin therapy, shifting immature and large reticulocytes into the circulation by Inoka et al. ${ }^{[46]}$.

\section{CONCLUSIONS}

With the focus of health of women in general and the adolescent girl in particular, the scenario of anemia is alarming. On the basis of data gathered in our study in unmarried anemic females, in terms of severity mild anemia was observed in $48 \%$ cases, moderate anemia was observed in $37 \%$ cases and severe anemia was observed in $15 \%$ cases. Anemia is thus impediment to individual and national development. With the fluency of study in terms of peripheral blood smear, $19 \%$ cases of normocytic normochromic anemia was obeserved,14\% cases of macrocytic anemia was observed and $67 \%$ of cases of microcytic anemia (most of them iron deficiency anemia) was observed. 
To prevent anemia at a low cost, it is recommended to provide women with relevant information and wellplanned interactive educational programs. We believe that further, more comprehensive studies with more subjects would make a considerable contribution to the knowledge base in this field.

\section{CONTRIBUTION OF AUTHORS}

Research concept- Dr. Neelima Singh

Research design- Dr. Neelima Singh

Supervision- Dr. Neelima Singh

Materials- Dr. Rahul Dudwe

Data collection- Dr. Rahul Dudwe

Data analysis and Interpretation- Dr. Neelima Singh

Literature search- Dr. Neelima Singh

Writing article- Dr. Rahul Dudwe

Critical review- Dr. Neelima Singh

Article editing- Dr. Rahul Dudwe

Final approval- Dr. Neelima Singh

\section{REFERENCES}

[1] WHO/UNICEF/UNU. Iron deficiency anemia assessment; prevention and control. A guide for programme managers. Geneva: WHO/ UNICEF/UNU, 2001.

[2] World Health Organization. Haemoglobin concentrations for the diagnosis of anemia and assessment of severity. Geneva: WHO; 2011 Available from: https://www.who.int/vmnis/indicators/haemoglobin /en/, 2019.

[3] Horton S, Ross J. The economics of iron deficiency. Food Policy, 2003; 28: 51-75. doi: 10.1016/S03069192(02)00070-2.

[4] Balarajan Y, Ramakrishnan UO, Zaltin E, Shankar AH, Subramanian SV. Anaemia in low-income and middle-income countries. Lancet, 2011; 378(9809): 2123-35. doi: 10.1016/S0140-6736(10)62304-5.

[5] Harding KL, Aguayo VM, Namirembe G, Webb P. Determinants of anemia among women and children in Nepal and Pakistan: An analysis of recent national survey data. Matern. Child. Nutr., 2018; 14(S4): e12478. doi: 10.1111/mcn.12478.

[6] Lee J-O, Lee JH, Ahn S, Kim JW, Chang H, Kim YJ, et al. Prevalence and risk factors for iron deficiency anemia in the korean population: results of the fifth Korea National Health and Nutrition Examination
Survey. J. Korean. Med. Sci., 2014; 29: 224-29. doi: 10.3346/jkms.2014.29.2.224.

[7] Adamu AL, Crampin A, Kayuni N, Amberbir A, Koole $O$, Phiri $A$, et al. Prevalence and risk factors for anemia severity and type in Malawian men and women: urban and rural differences. Popul. Health Metr., 2017; 15: 12. doi: 10.1186/s12963-017-01282.

[8] Balarajan YS, Fawzi WW, Subramanian SV. Changing patterns of social inequalities in anaemia among women in India: cross-sectional study using nationally representative data. BMJ Open, 2013; 3(3): e002233. doi: 10.1136/bmjopen-2012-002233.

[9] Ackerson LK, Subramanian SV. Domestic violence and chronic malnutrition among women and children in India. Am. J. Epidemiol., 2008; 167(10): 1188-96. doi: 10.1093/aje/kwn049.

[10]Bethony J, Brooker S, Albonico M, Geiger SM, Loukas $A$, Diemert $D$, et al. Soil-transmitted helminth infections: ascariasis, trichuriasis, and hookworm. Lancet, 2006; 367: 1521-32. doi: 10.1016/S01406736(06)68653-4.

[11]Menendez C, Fleming AF, Alonso PL. Malaria-related Anaemia. Parasitol. Today, 2000; 16: 469-76. doi: 10.1016/S0169-4758(00)01774-9.

[12] O'Brien ME, Kupka R, Msamanga GI, Saathoff E, Hunter DJ, et al. Anemia is an Independent Predictor of Mortality and Immunologic Progression of Disease Among Women With HIV in Tanzania. J. Acquir. Immune. Defic. Syndr., 2005; 40. doi: 10.1097/01.qai.0000166374.16222.a2.

[13] Haile ZT, Kingori C, Teweldeberhan AK, Chavan B. The relationship between history of hormonal contraceptive use and iron status among women in Tanzania: A population-based study. Sex Reprod. Healthcare, 2017; 13: 97-102. doi: 10.1016/j.srhc.2017.07.003.

[14]Katai E, Kaplan B, Raick Y, Cohen Y, Neri A, et al. Community screening to reveal iron deficiency in healthy menstruating women in Israel suburbs. Eur. J. Obstet. Gynecol. Reprod. Biol., 1996; 67: 21-25.

[15]Milman N, Rosdahl N, Lyhne N, Jorgensen T, Graudal N. Iron status in Danish women aged 35-65 years. Relation to menstruation and method of contraception. Aca. Obstet. Gynecol. Scand., 1993; 72: 601-05. 
[16]Basturk A, Kutlucan L, Kutlucan A, Pekin AT, Akinci S, et al. Evaluation of pregnant women awareness about anemia and factors affecting the development of anemia. Eur. J. Health Sci., 2016; 2(1): 14. doi: 10.5505/eurjhs.2016.46855.

[17]Karakus V, Giden A, Ersil SD, Bozkurt S, Kurtoglu E. Evaluation of anemia in terms of etiology, risk factors, and relapse in adult patients. Mugla. Med. J., 2016; 3: 1-6.

[18]Lindsay HA. Pregnancy and iron deficiency anaemia: unresolved issues. Nutr. Rev., 1997: 91-101.

[19]Milman N, Bergholt T, Byg KE, Eriksen L, Graudal N. Iron status and iron balance during pregnancy. A critical reappraisal of iron supplementation. Acta. Obstet. Gynecol. Scand., 1999; 78: 749-57.

[20]Brabin B, Piper C. Anaemia- and malaria-attributable low birthweight in two populations in Papua New Guinea. Ann. Hum. Biol., 1997; 24: 547-55.

[21]Fleming AF. HIV and blood transfusion in subSaharan Africa. Transfus. Sci., 1997; 18: 167-79.

[22]UNICEF. Preventing iron deficiency in women and children. Technical concensus on key isues. UNICEF/UNU/WHO/MI. Technical workshop, New York, 1998.

[23]Van de Broek NR, Letsy EA, White SA, Shenkin A. Iron status in pregnant women: which measurements are valid? Br. J. Haematol., 1998; 103: 817-24.

[24]Rawat CM, Garg SK, Singh VJ, Bhatnagar M, Chopra $\mathrm{H}$, et al. Socio-demographic co- relates of anemia among adolescent girls in rural area of district Meerut (U.P). Ind. Commun. Med., 2001; 26: 4.

[25]Verma A, Rawal VS, Kedia G, Kumar D, Chauhan J. Factors infl uencing anemia among girls of school going age (6-18 yrs) from slums of Ahmedabad City. Ind. J. Commun. Med., 2004; 24: 1.

[26]Bukar M, Audu BM, Sadauki HM, Elnafaty AU, Mairiga AG, Prevalence of iron deficiency and megaloblastic anaemia at booking in a secondary Health facility in North Eastern Nigeria. Nigerian J. Med., 2009; 50(2): 33-37.

[27]Kanani S, Poojara RH. Supplementation with iron folic acid enhances growth in adolescent Indian girls. J. Nutr., 2000; 130: 452S-55.

[28]Alene KA, Dohe AM, Prevalence of anaemia and associated factors among pregnant women in an urban area of eastern Ethiopia. Anemia; 2014; pp. 17 doi: $10.1155 / 2014 / 561567$.
[29]Gebre A, Mulugeta A. Prevalence of Anemia and Associated Factors among Pregnant Women in North Western Zone of Tigray, Northern Ethiopia: A Cross Sectional Study. J. Nutr. Metabolism, 2015; pp. 1-7. doi: 10.1155/2015/165430.

[30]Ononge S, Campbell O, Mirembe F. Haemoglobin status and predictors of anaemia among pregnant women in Mpigi, Uganda. BMC Res. Notes, 2014; 7: 712.

[31]Nwizu EN, Iliyasu Z, Ibrahim SA, Galadanci HS, SocioDemographic and Maternal Factors in Anaemia in Pregnancy at Booking in Kano, Northern Nigeria. Afr. J. Reprod. Health, 2011; 15(4): 411.

[32]Fujimori E, Sato APS, Szarfarc SC, et al. Anaemia in Brazilian pregnant women before and after flour fortification with iron. Public Health Magazine, 2011; 45(6): 1027-35.

[33]Thirukkanesh S, Zahara AM. Compliance to vitamin and mineral supplementation among pregnant women in urban and rural areas in Malaysia, Pak. J. Nutr., 2010; 9(8): 744-50.

[34]Khan DA, Fatima S, Imran R, Khan FA. Iron, folate and cobalamin deficiency in anaemic pregnant females in tertiary care centre at Rawalpindi. J. Ayub. Medical College, Abbottabad, 2010; 22(1): 17-21.

[35]Aikawa R, Khan NC, Sasaki S, Binns CW. Risk factors for iron-deficiency anaemia among pregnant women living in rural Vietnam. Public Health Nutr., 2006; 9(4): 443- 48.

[36]Koblinsky M. Anaemia KM. Women's health. Mother Care Matters, 1994; 4: 2-13.

[37]Van den Broek NR, Ntonya C, Mhango E, White SA. Diagnosing anaemia in pregnancy in rural clinics: assessing the potential of the Haemoglobin Colour Scale. Bull. World Health Organ., 1999; 77: 15-21.

[38]Ingram CF, Lewis SM. Clinical use of WHO haemoglobin colour scale: validation and critique. J. Clin. Pathol., 2000; 53: 933-37.

[39]Shulman CE, Graham WJ, Jilo H, et al. Malaria is an important cause of anaemia in primigravidae: evidence from a district hospital in coastal Kenya. Trans. R. Soc. Trop. Med. Hyg., 1996; 90: 535-39.

[40]Antelman G, Msamanga Gl, Spiegelman D, et al. Nutritional factors and infectious disease contribute to anemia among pregnant women with human immunodeficiency virus in Tanzania. J. Nutr., 2000; 130: 1950-57. 
[41]Zucker JR, Lackritz EM, Ruebush TK et al. Anaemia, blood transfusion practices, HIV and mortality among women of reproductive age in western Kenya. Trans. R. Soc. Trop. Med. Hyg., 1994; 88: 17376.

[42]Van den Broek NR, Letsky EA. Etiology of anemia in pregnancy in south Malawi. Am. J. Clin. Nutr., 2000; 72: 247S-56S.

[43]Tatala S, Svanberg U, Maduma B. Low dietary iron availability is a major cause of anemia: nutrition survey in the Lindi District of Tanzania. Am. J. Clin. Nutr., 1998; 68: 171-78.
[44]Stoltzfus RJ, Chwaya HM, Tielsch JM, Schulze KJ, Albonico $\mathrm{M}$, et al. Epidemiology of iron deficiency anemia in Zanzibari schoolchildren: the importance of hookworms. Am. J. Clin. Nutr., 1997; 65: 153-59.

[45]Atukorala TMS, de Silva LDR, Dechering WHJC, Dessanaike TSC, Perera RS. Evaluation of effectiveness of iron-folate supplementation and anthelminthic therapy against anaemia in pregnancy: A study in the plantation sector of Sri Lanka. Am. J. Clin. Nutr., 1994; 60: 286-92.

[46]Inoka P. Anemia in chronic kidney disease in children. Reviews. Galle Med. J., 2007; 12(1): 27. 